\title{
PREDICTION OF HIGH-PERFORMANCE FIBER- REINFORCED POLYMER CONCRETE USING FUZZY NEURAL NETWORK PROTOTYPES
}

\author{
N. Raghuraman \\ Proprietor, M/S NRRAGHURAM \&CO engineers \& valuers an engineering services \\ company \\ ${ }^{* 1}$ Email: nraghuraman4@gmail.com
}

\begin{abstract}
$R C$ building elements of Reinforcing and upgrading is essential to extend its maintenance time, to overcome first structural limitations, and to control the consequence of building construction or design flaws. The RC constructions are reinforced by using the FRP-fiber reinforced polymer. This study utilizes the FRP in concrete structures for instance a Jute, coir, and Sisal is explored for its reliability in improving ductility and strength related structural performance. FRP structural response of the model parameters is studied by measuring the numerical and experimental terms, for instance, Ductility, Deflection, Tensile-Strength, and Compression-Strength. The quality of the sample specimens is tested by using the Fuzzy Neural Network (FNN) system. At this time, compared with existing jobs, the propounded Fuzzy Neural Network model accomplishes the best presentation regarding all boundaries for the fiberreinforced specimen over different stacked conditions.
\end{abstract}

Keywords: Ductility, fiber reinforced polymer, compressive strength, deflection, tensile strength, Reinforced Concrete-RC, Fuzzy Neural Network-FNN.

\section{INTRODUCTION}

In the most recent decades, the use of Fiber-Reinforced Concrete for the renovation of existing structures is increasing across the board. Renovation is the correction of the current buildings to enhance the output and structural durability [1-2]. Regular renovation procedures, such as, outer-jacket using steel plates, and concrete extension division, etc. These are widely used in regular day [3]. Use of FR compounds to repair reinforced concrete buildings has emerged as one more and appropriate result [4] The light weight fiber reinforced polymers are, gradually strong, and higher solidarity to-weight ratios than standard invigorating substances, for instance, steel, and bring about low duty incremented and low gear concentrated restructuring works [5-6]. The fiber reinforced polymers (FRP) compounds contain few remarkable characteristics, for instance, assurance from corrosion, Damping obstruction and incredible exhaustion, Electromagnetic straightforwardness, and bigger strength to mass proportion [7]Later, for scientists, designers, and researchers, the natural fibers are attractive choices, for their selective help for fiber reinforced polymer (FRP) compounds due to their simplicity, truly 
superior Mechanical characteristics, ruggedness, high apparent power, ecological type etc. [810]. Everything is completed, the sisal fiber is unbelievably strong and lower maintenance with excellent services, and SF is greater than the materials and surfaces additionally, restructuring with FRP may gradually give you a better option than conservative and actually conventional techniques.

FRPs are light weight, durable and have a high strength-to-weight ratio when compared to conventional reinforcing substances, such as, steel which will increase low workload and lower gear intensive restructuring works [11-12]. However, this testing procedure contains some problems, for instance, the long development period due to the relief requirements and the complexity of the development and establishment patterns in general that prevent costs. Improvement procedures are used to identify these systems, to determine the functionality of the buildings, and FRP model's strength are used to predict the development of processes [1314]. Utilization of NN to improve prognosis and concrete properties is another area of research in general, and late selections have revealed that NNs are unique in Machine Learning (ML) gadgets for some reasons [15-17]. From the guidance of such Algorithms, Mass, and Strength or quality of few buildings are extended. The simulation modeling and test for achieving the tip top of FRC buildings are shown in this presentation. We utilized regular Fiber for better performance of CS when compared to find the buildings conduct. For endorsement cause, OFNN is used to foresee the mechanical features are ideally when contrasted and test and current frameworks.

\section{LITERATURE REVIEW}

SaeidTarfan et al. in 2018 [18] had exhibited the Probability seismic evaluation of non-flexible reinforced concrete buildings reconstructed by pre-tensioned aramid FRP. By using Concentrated Plastic Pivot samples, the Numerous Finite Element are made, which captures the individual sections shear defect, distortion of stiffness, and strength of the beams. Prem Paul Bansal and Raju Sharma [19] was presented the trail experiment to evaluate the reliability of the reuse of Ultra-High-Performance Hybrid FRC (UHP-HFRC), and (UHP-HF). Reuse outside the Joint of BEAM-COLUMN. In 2018 Francisco J. Rescalvo et al. [20] demonstrated a theory to verify wood rods with CFRP-carbon fiber reinforced polymer by the Sound emission system. This impact was especially promising to watch the wellbeing of the reestablished wood parts in real conditions.

The dynamic carry out of eroded RC segments were studied to re-establish. Retrofitting materials consisting of high-performance fiber reinforced concrete HPFRC and GFRP coatings was examined by Aditya Singh Rajput et al. [21]. Implementation of column models was rated as an important strength and ductility pointers. Decent vertical post-reaction was one of the major weaknesses of these restructuring methods.

Xiaoshuang Xiong et al. [22] Multi-scale system models were evaluated to study the mechanical properties of plain-woven composites. The expected results from the multidimensional system model demonstrated excellent collaboration from finite element analysis and experimental analysis. The Finite Element simulation of reinforced cement 
concrete beam remodeling utilizing Sisal-Fiber composites are recommended. To evaluate the sisal fiber performance in primary restructuring, utilization plain blocks of concrete with sisal fiber reinforced polymer. The Madhavan K Mini et al. [24] was proposed ANN (ARTIFICIAL NEURAL NETWORK) models were demonstrated to estimate the sad lives of unilateral glass fiber-reinforced epoxy-based compounds under strain pressure and strain pressure pile. A blend of FUZZY system and NN is used in the current selection, and an equivalent detail has been made to obtain a better system.

\subsection{Research interval}

The existing inquiries and literature were guided, the gain of thought about the depiction of fibers in the modeling process and structural design. Any invention or object has its controls and must be developed and used to meet new requirements. Of late, the structures do not comply with the bill for the existing weighty load precondition, and this way of the restoration of this building is necessary. The one of the better options to safely replace an existing defective building opposed to upcoming earthquakes or various environmental forces. Easy approach to strengthening buildings to twist the threads by two symmetrical titles. Existing methods to reassembling Steel bridges and constructions typically utilizing steel plates, which was fired or connected to the structures. At any situation, structural and life defects are associated with such method. Steel plates and structure requires heavy lifting hardware add significant dead loads, reducing its level of reinforcement sufficiently. To overcome the problems, the use of fiber reinforced polymer (FRP) framework for the reuse of concrete structures has been successful

\section{EXPERIMENTAL INVESTIGATION: HPFRC}

This strategy presents a trial study to investigate the conduct of natural fibers utilized HPFRC (cubes, beam-column, and cylinder) for natural fibers such as jute, coir and sisal. Made of HPFRC cement M20 grade, it has 53 grade of ordinary Portland cement (OPC) mix ratio, coarse aggregate and little admixture with a distinct amount. Functional code for plain and strengthened concrete is arranged and tried to IS 456 - 2000 standards. Figure 1 exhibited three sorts of models.

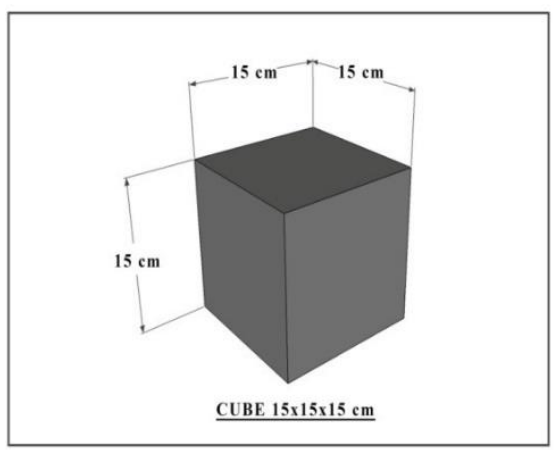

(a) Cube

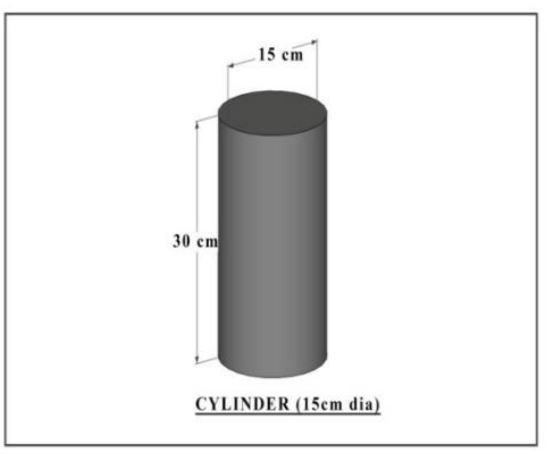

(b) Cylinder 


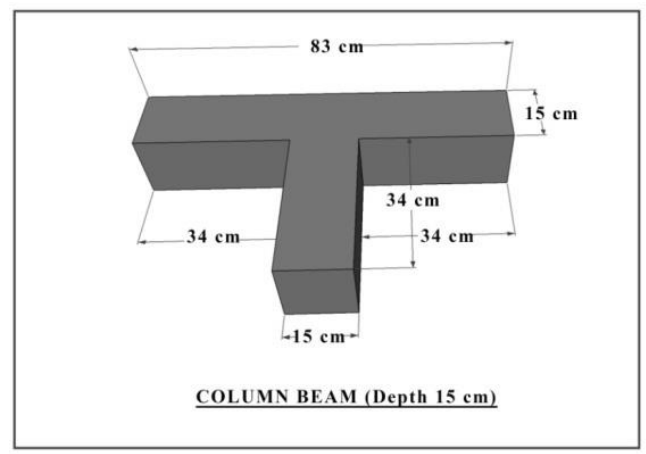

(c) Beam-column joint

Fig.1: RC structures dimensions - (a) Cube, (b) Cylinder and (c) Beam- column joint

\section{MATERIAL TESTING}

The propounded investigation, the materials utilized for preparing samples are delineated as M20 concrete grade (water, cement, fine aggregate, and coarse aggregate) alongside fiber reinforced polymers (FRP). M20 grade of concrete's mix design ratio is 1:1.5:3, it was clustered for mixing. Concrete was prepared based on the mixing ratio Utilizing the volume of batching, and set in the corresponding sections. In the FRP is considered as flexible, Until the pressure reaches its tensile strength, vulnerability to create cracks after strain reducing to zero, In the propounded work, the features of fiber reinforced polymer (FRP) materials analyzed are coir, jute, and sisal.

Table 1: Concrete mix ratio

\begin{tabular}{|c|c|c|c|c|}
\hline Mixing ratios & $\begin{array}{c}\text { Cement } \\
\left(\mathbf{k g} / \mathbf{m}^{\mathbf{3}}\right)\end{array}$ & $\begin{array}{c}\text { Fine aggregate } \\
\left(\mathbf{k g} / \mathbf{m}^{\mathbf{3}}\right)\end{array}$ & $\begin{array}{c}\text { Coarse aggregate } \\
\left(\mathbf{k g} / \mathbf{m}^{\mathbf{3}}\right)\end{array}$ & $\begin{array}{c}\text { Water } \\
\left(\mathbf{k g} / \mathbf{m}^{\mathbf{3}}\right)\end{array}$ \\
\hline M-20 & 400 & 693 & 1377 & 180 \\
\hline
\end{tabular}

\subsection{Types of fiber}

(a) Jute fiber: This is one of the least effort natural fibers, and it is also made of bast fiber with a very intense generation size. This fiber contains low security from moisture, corrosion, and ultra violet (UV) light. The excellent structure and their protection from heat and fire provide an infinite opportunity of applications in companies, for instance, development, car, and material.

(b) Coir fiber: It consists of pragmatically equal cellulose and lignin. In the process of biosoftening, lignin is expelled and cellulose takes place. This is increasingly the white shade and extended fiber provides elasticity and extensibility attributes.

(c) Sisal fiber: At present, there is many researches focusing on the potential of reinforced composites of Sisal-Fibers. To use fiber compounds in many applications, it is essential to have certain mechanical properties such as greater tensile strength and less wear. 


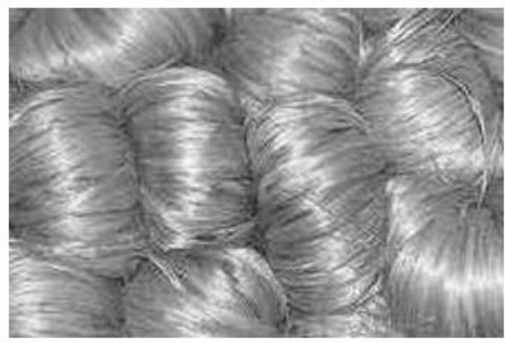

(a)

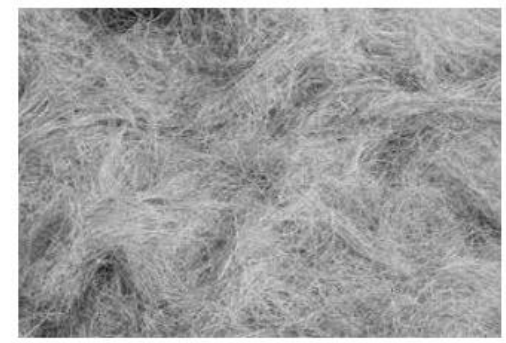

(b)

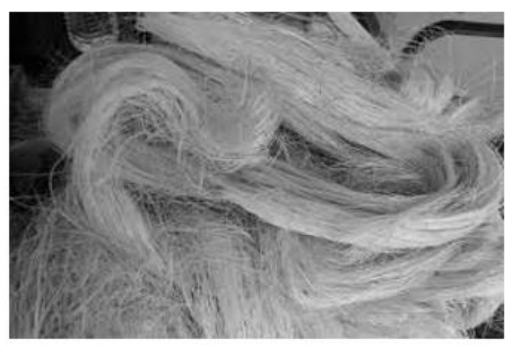

(c)

Fig. 2: (a) Jute, (b) Coir, (c) Sisal

Table 2: Fiber Properties

\begin{tabular}{|c|c|c|c|c|c|}
\hline SI.No & $\begin{array}{c}\text { Fiber reinforced } \\
\text { polymer- } \\
\text { materials type }\end{array}$ & $\begin{array}{c}\text { Tensile } \\
\text { strength } \\
\text { (mpa) }\end{array}$ & $\begin{array}{c}\text { Modulus of } \\
\text { elasticity } \\
\text { (gpa) }\end{array}$ & $\begin{array}{c}\text { Elongation at } \\
\text { failure (\%) }\end{array}$ & $\begin{array}{c}\text { Density } \\
\text { G/m3 }\end{array}$ \\
\hline 1 & JFRP & $410-780$ & $10-30$ & $1.5-1.8$ & 1.48 \\
\hline 2 & CFRP & 500 & $16-26$ & 17 & $1.25-1.5$ \\
\hline 3 & SFRP & $126-860$ & $9-22$ & $2-7$ & $1.28-1.42$ \\
\hline
\end{tabular}

\subsection{Specimen test detail}

The test samples were split into two divisions: control- fiber reinforced polymer (jute, Coir, and sisal).

(a) Control samples: The M-20 standard has three features, namely CS1, CS2 and CS3, in various three formats, for instance a cube, cylinder and beam-column.

(b) Strengthened FRP samples: This includes nine models of m20 concrete grade with fiber materials in unique three structures, for example, a cylinder, beam-column, and cube. HPC of each model, M20 grade of concrete models strengthened with sisal FRP, M20 grade strengthened with jute FRP and strengthened with M20 grade Coir fiber reinforced polymer (FRP).

Table 3: Details of specimens

\begin{tabular}{|c|c|c|c|c|}
\hline \multirow{2}{*}{ S. No. } & \multirow{2}{*}{ Specimen } & \multicolumn{3}{|c|}{ Specimen-signs } \\
\cline { 3 - 5 } & & Cube & Cylinder & Column \\
\hline 1 & Control-Specimen & CS-1 & CS-2 & CS-3 \\
\hline 2 & \multirow{3}{*}{ FRP-Specimen } & SFRP & SFRP & SFRP \\
\hline \multirow{nnyyy}{nnnyy}{} & & JFRP & JFRP & JFRP \\
\cline { 3 - 5 } & & CFRP & CFRP & CFRP \\
\hline 4 & & & & \\
\hline
\end{tabular}




\subsection{Preparation of specimens}

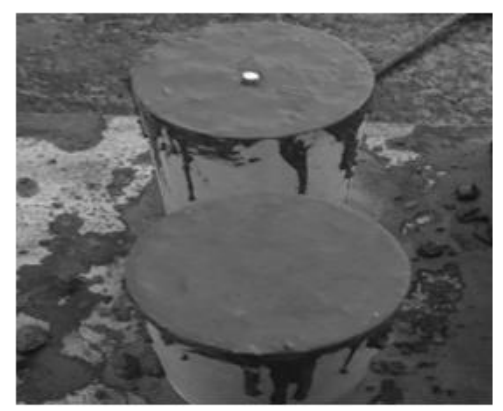

(a)

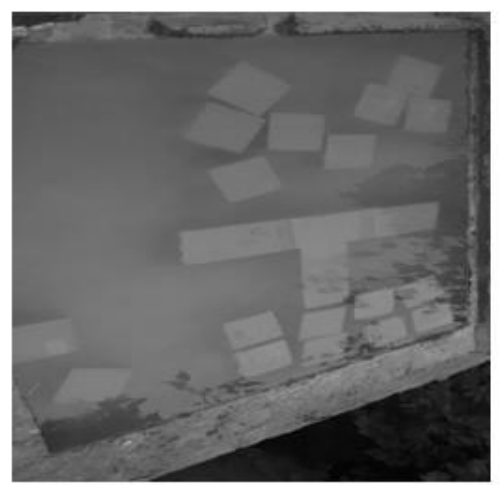

(d)

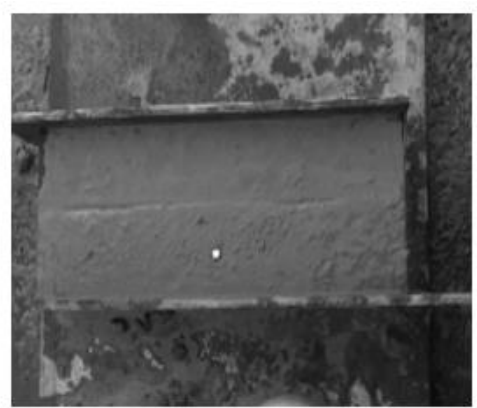

(b)

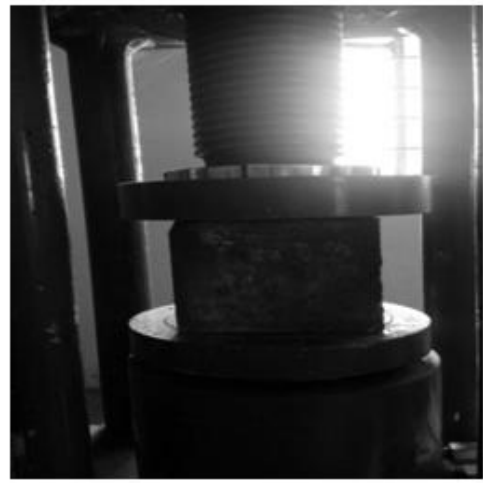

(e)

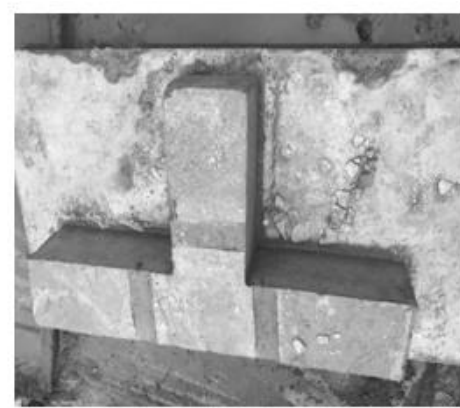

(c)

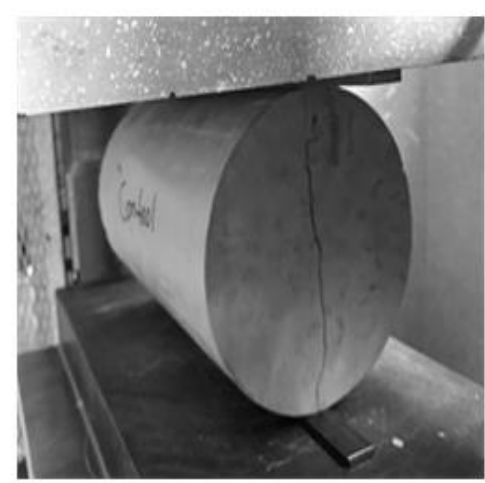

(f)

Fig. 3: (a) Cylinder, (b) Cube, (c) Beam-column specimen, (d) Curing specimens

(e) Testing specimens (f) Tested cylinder specimen

Until the formation of cracks in the samples were subjected to cyclic loading. For each sample tested individually for each sample of the deflection, the load limit and the mechanical properties are expressed. This test was performed in MATLAB soft computer technology approved by the performance of the models.

\subsection{Investigation of FNN-analysis}

Using experimental models, the load-bearing capacity of each model and the mechanical properties, Simulation analysis exploring the different conditions i.e., the FNN. The use of the fuzzy neural network executes the better solution and initiates the input parameter problems (e.g., member functions) for evaluation.

\subsubsection{FNN's execution}

An obscure FNN follows 4 layers: 1) an input layer such as the first BPNN or RBFNN, which contributes to the following layer only for fans; 2) A hidden layer, e.g., Variables; 3) The rule layer, the bolt from some fuzzifying node indicates the next ambiguous variables in this layer; and 4) confusion layer; its diagrams represented in fig 4. 
(a) Input layer: We establish the input parameters to examine the response of HPFRC constructions such as cylinder, cubes, and beam-column joints are made with nature fibers, for instance, Density, load, Young's modulus, Tensile-Strength and fiber-varieties for each model. Indicates are denotes the input parameters.

$$
C_{i}=\left\{C_{1}, C_{2}, C_{3}, \ldots \ldots C_{n}\right\}
$$

(b) Member function layer: This layer functions at each node is a member of the input variables in the input layer corresponds to one linguistic label. It is estimated that over the smooth entry of the ambiguous quality of each fuzzy member.

$$
f 2=\mu_{i}=\exp \left[-\left(\frac{C_{i}-r_{i j}}{s_{i j}}\right)^{2}\right]
$$

Where $\mu_{i}$ - fuzzy membership function, $C_{i}$ - the input of FNN, $r_{i j}$-the center and $s_{i j}$ - width in jth a fuzzy set of the ithinput.

(c) Rule layer: In this layer the nodes are characterizes the one fuzzy logic rule and do the precondition matching of a rule. Here, we use the $\Pi$ operation (AND) for each Layer 2 node.

Rule 1: $\mathrm{f} 1=(\mathrm{p} 1 \mathrm{x}+\mathrm{q} 1 \mathrm{y}+\mathrm{r} 1)$ where, $(\mathrm{x}$ is $\mathrm{A} 1)$ and $(\mathrm{y}$ is $\mathrm{B} 1)$

Rule 2: $f 2=(p 2 x+q 2 y+r 2)$ where, $(x$ is $A 2)$ and $(y$ is $B 2)$

Likewise, the initialized parameters-based rules are generated. For each rule, its calculated weight is as the product of the input membership values as:

$$
f 3=G_{j}=\prod_{i=1}^{n} \mu_{i}
$$

Where $G_{j}$ - the rule generated layer's weight, n -number of input parameters considered in the fiber reinforced polymer samples. The outcome of the layer node shows that the terminating quality of the corresponding fuzzy rule. 


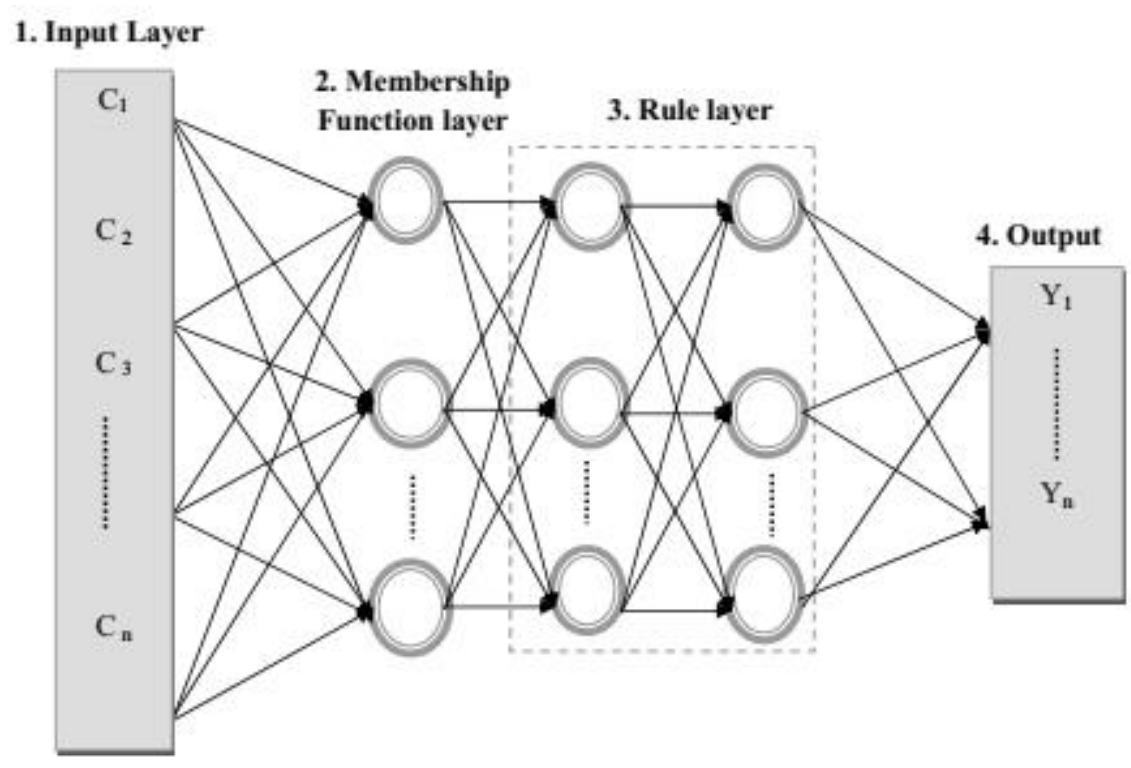

Linguistic Variables

Fig 4: Structure of FNN

(d) Output layer: The eventual layers are called the clarifying layers and also known as the defuzzification layers. In this layer the single node is denoted as $\Sigma$, it calculates the total output as the sum of entire Input-Signals.

$$
f 4=\sum_{i=1}^{N} O_{i} \times C_{i}+O_{0}
$$

Here, $O_{i}$ - Connecting weight which is the output power action of the $4^{\text {th }}$ layer output correlated with the $3^{\text {rd }}$ layer rule, and the scalar $O_{0}$ is a bias. By implementing these fuzzy neural network (FNN)parameters, we will examine the tensile strength, deflection, compressive strength behavior of every samples.

\section{RESULT ANALYSIS}

The introduced FRP concrete's structural analysis response with the distinctive example (for block, chamber and shaft section) is completed in the working phase of windows machine having designs as windows 7, Intel (R) Core i5 processor, $1.6 \mathrm{GHz}, 4 \mathrm{~GB}$ RAM, and under the various load condition are used to test the properties in the MATLAB process.

\subsection{Parameter's test}

Compressive strength $(\mathbf{N} / \mathbf{m m} \mathbf{2})$ : The compressive strength of every substance is classified into the load attached to the failure point.

Tensile Strength: This is the ability of an object to withstand a tensile barrier. It is usually calculated in force units for the cross-sectional area. 
Deflection: Under a load deflection distance of a segment beneath a load is apparently related to the slope of the deflected shape of the area under loads.

Ductility: The factors of ductility can be classified as the rate of deviation at the point of failure or the deflection at the output or first crack.

Table 4: Compressive strength and tensile strength outcomes of cylinder and cube samples

\begin{tabular}{|c|c|c|c|c|c|}
\hline \multirow{3}{*}{ Sl.no } & \multirow{3}{*}{ Specimen } & \multicolumn{2}{|c|}{ Cube } & \multicolumn{2}{|c|}{ Cylinder } \\
\hline & & \multicolumn{2}{|c|}{$\begin{array}{l}28 \text { Days of compressive } \\
\text { strength in } \mathrm{N} / \mathrm{mm}^{2}\end{array}$} & \multicolumn{2}{|c|}{$\begin{array}{l}28 \text { Days of tensile strength in } \\
\qquad \mathrm{N} / \mathrm{mm}^{2}\end{array}$} \\
\hline & & experimental & FNN & experimental & FNN \\
\hline 1 & SFRP & 32.85 & 33.09 & 6.24 & 6.23 \\
\hline 2 & JFRP & 32.17 & 32.59 & 5.32 & 5.35 \\
\hline 3 & CFRP & 35.39 & 35.41 & 6.79 & 6.81 \\
\hline 4 & CS-1 & 31.69 & 31.69 & 4.90 & 4.89 \\
\hline 5 & $\mathrm{CS}-2$ & 32.19 & 31.74 & 5.04 & 4.97 \\
\hline
\end{tabular}

5.2. The compression strength under cyclic loading

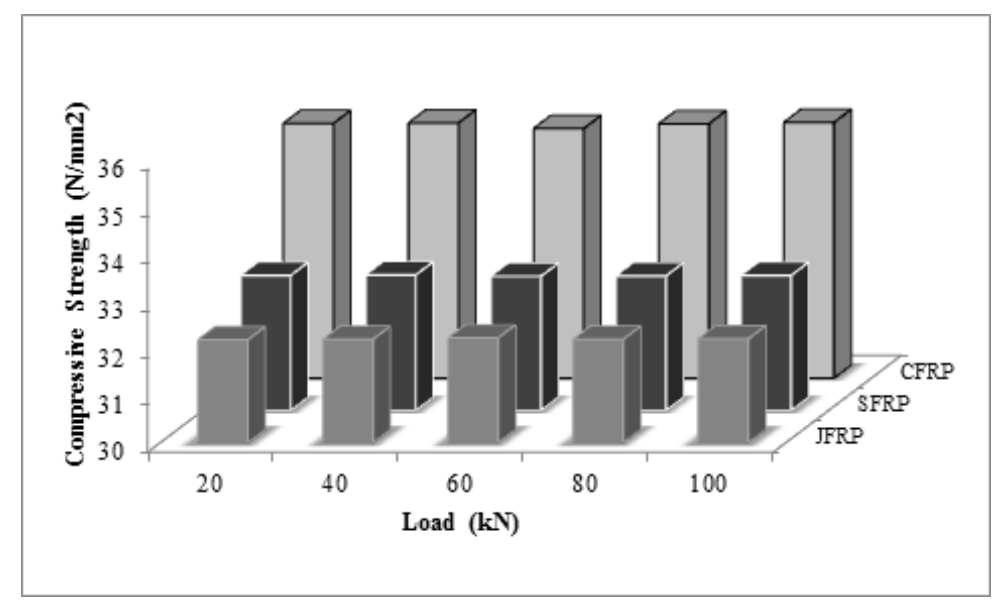

Fig. 5: Cube sample's compression strength

CS is usually derived from concrete samples examining of cylinder or cube figures with different dimensions propounded by different standards and codes. The CS of cured concrete cubes utilizing the identified methods was find-out in 28 number of days. Diagram 5 outlines the CS conduct of the fiber reinforced polymer (FRP) cube models JFRP, SFRP, and CFRP in various mounted positions. The diagram clearly represents that compressive strength (CS) increments with load state. This diagram unmistakably represents that the FRP model achieves higher CS contrasted with the control model and JFRP, CFRP, SFRP. 


\subsection{Tensile strength under cyclic loading}

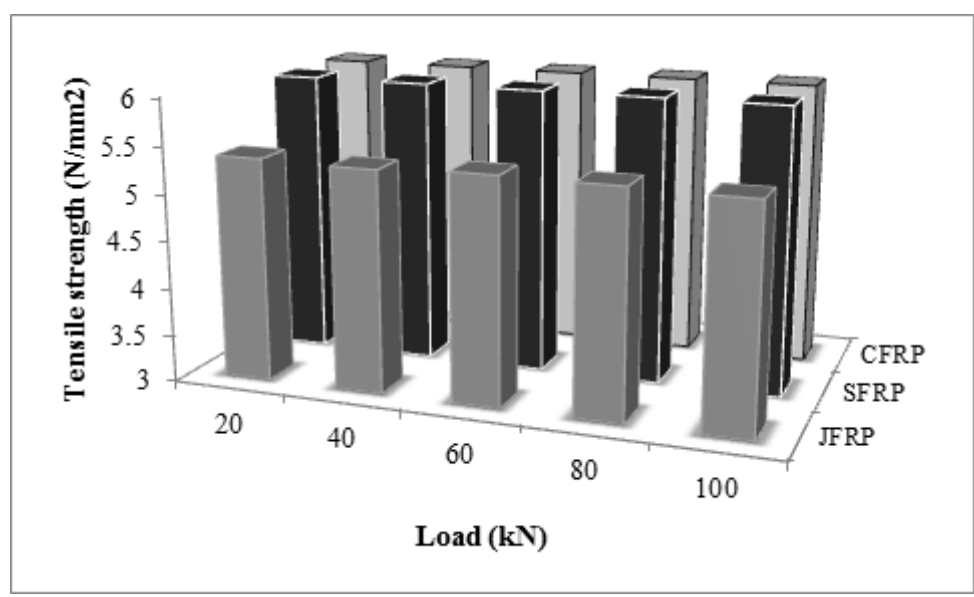

Fig. 6: Tensile strength- cylinder

Fig 6 explains the concrete mix ratio's tensile strength under the condition loaded to the cylinder models. FRP model clearly illustrates the TS manners of SFRP, JFRP, and CFRP for only 28 curing days with a bar diagram. The diagram clearly shows that the TS increment depending on the load condition. High tensile strength is achieved at 28 days of testing compared to sample curing days.

Table 5: Column specimen -deflection results

\begin{tabular}{|c|c|c|c|c|c|c|c|c|c|c|c|c|}
\hline \multirow{3}{*}{$\begin{array}{c}\text { Input } \\
\text { (Load) } \\
(\mathbf{k N})\end{array}$} & \multicolumn{12}{|c|}{ DEFLECTION in $\mathrm{mm}$} \\
\hline & \multicolumn{2}{|c|}{ CS } & \multicolumn{2}{|c|}{ SFRP } & \multicolumn{2}{|c|}{ JFRP } & \multicolumn{2}{|c|}{ CFRP } & \multicolumn{2}{|c|}{ R_GFRP } & \multicolumn{2}{|c|}{ R_BFRP } \\
\hline & $\begin{array}{c}\text { Expe } \\
\text { rime } \\
\text { ntal }\end{array}$ & $\begin{array}{c}\text { FN } \\
\mathbf{N}\end{array}$ & $\begin{array}{c}\text { Exper } \\
\text { iment } \\
\text { al }\end{array}$ & FNN & $\begin{array}{c}\text { Exper } \\
\text { iment } \\
\text { al }\end{array}$ & $\begin{array}{c}\text { FN } \\
\mathbf{N}\end{array}$ & $\begin{array}{c}\text { Exper } \\
\text { iment } \\
\text { al }\end{array}$ & $\begin{array}{c}\text { FN } \\
\mathbf{N}\end{array}$ & $\begin{array}{c}\text { Exper } \\
\text { iment } \\
\text { al }\end{array}$ & $\begin{array}{c}\mathbf{F N} \\
\mathbf{N}\end{array}$ & $\begin{array}{c}\text { Exper } \\
\text { iment } \\
\text { al }\end{array}$ & FNN \\
\hline 0 & 0 & 0 & 0 & 0 & 0 & 0 & 0 & 0 & 0 & 0 & 0 & 0 \\
\hline 5 & 0.5 & 0.58 & 0.5 & 0.53 & 1.5 & 1.2 & 1.8 & 1.75 & 1.8 & 1.79 & 2.8 & 2.871 \\
\hline 10 & 2.4 & 2.5 & 2.8 & 2.75 & 2.6 & 2.32 & 3.7 & 3.82 & 3.5 & 3.58 & 3.5 & 3.52 \\
\hline 15 & 5.8 & 5.75 & 4 & 4.18 & 5.2 & 5.1 & 5.2 & 5.45 & 5.4 & 5.45 & 5.3 & 5.35 \\
\hline 20 & 7.2 & 7.35 & 5.4 & 4.56 & 4.7 & 4.8 & 6.4 & 6.3 & 6.7 & 6.72 & 6.4 & 6.42 \\
\hline 25 & 8.6 & 8.71 & 7.4 & 5.5 & 6.5 & 6.78 & 7.23 & 7.18 & 7.25 & 7.3 & 7.5 & 7.6 \\
\hline 30 & 8.2 & 8.14 & 8.6 & 6.4 & 6.8 & 7.14 & 7.3 & 7.37 & 7.74 & 7.55 & 7.63 & 7.74 \\
\hline
\end{tabular}




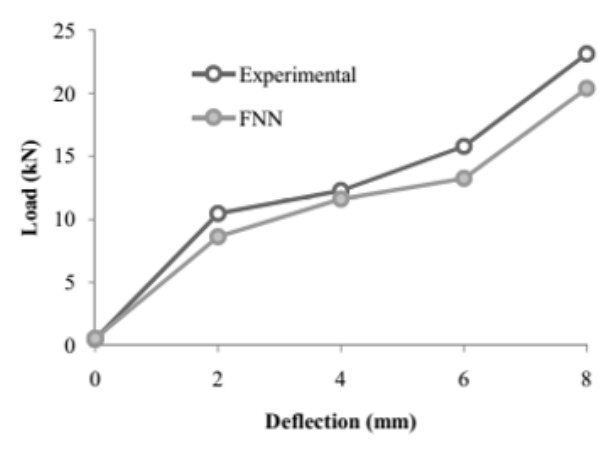

(a) CS

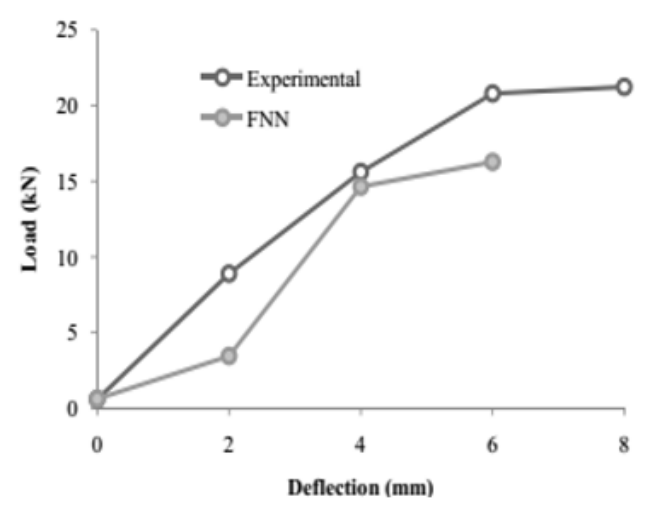

(c) JFRP

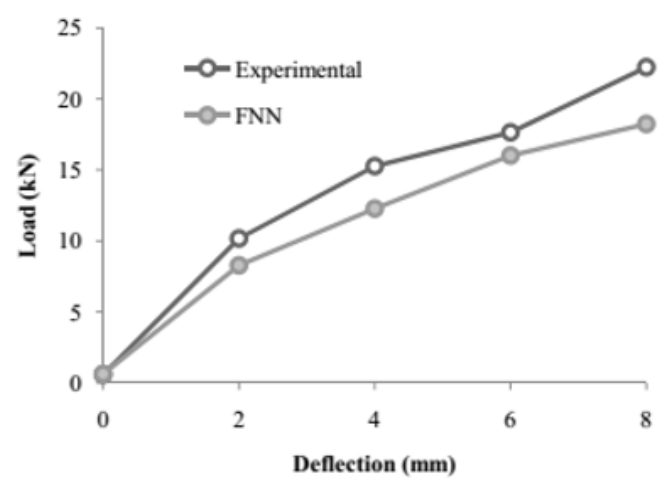

(b) SFRP

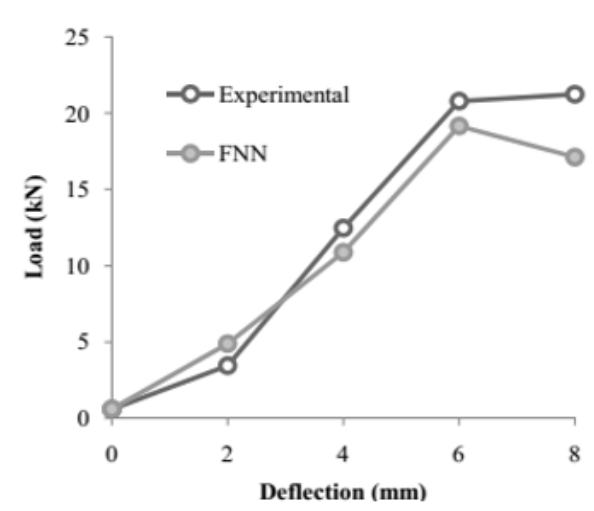

(d) CFRP

Fig 7: Beam-column specimen's deflection analysis (a) CS, (b) SFRP, (c) JFRP, (d) CFRP

Table-5 illustrates the three group models deflection value (control, fiber reinforced polymerFRP). Tabulation contrasts the test and anticipated estimations of the BEAM-COLUMN model's deflection. The proposed approach with FNN six beam-column samples is examined tested in the simulation analysis. Diagram 7 illustrates the six VARIOUS beam-column model's Load and Deflection curves, for instance SFRP, CFRP, CS, and JFRP.

Table 6: Beam-Column Ductility

\begin{tabular}{|c|c|c|c|c|c|c|c|c|c|c|c|c|}
\hline \multirow{3}{*}{$\begin{array}{c}\text { Input } \\
\text { (Load) } \\
(\mathbf{k N})\end{array}$} & \multicolumn{12}{|c|}{ Ductility in mm } \\
\hline & \multicolumn{2}{|c|}{ CS } & \multicolumn{2}{|c|}{ SFRP } & \multicolumn{2}{|c|}{ JFRP } & \multicolumn{2}{|c|}{ CFRP } & \multicolumn{2}{|c|}{ R_GFRP } & \multicolumn{2}{|c|}{ R_BFRP } \\
\hline & Actual & FNN & Actual & FNN & Actual & FNN & Actual & FNN & Actual & FNN & Actual & FNN \\
\hline 0 & 0 & 0 & 0 & 0 & 0 & 0 & 0 & 0 & 0 & 0 & 0 & 0 \\
\hline 5 & 3.24 & 3.31 & 4.11 & 4.13 & 5.1 & 5.23 & 5.75 & 5.77 & 5.81 & 5.85 & 5.91 & 5.92 \\
\hline 10 & 4.22 & 4.25 & 4.85 & 4.87 & 5.21 & 5.22 & 5.77 & 5.74 & 5.82 & 5.87 & 5.94 & 5.96 \\
\hline 15 & 5.11 & 5.18 & 5.62 & 5.66 & 5.16 & 5.45 & 5.81 & 5.88 & 6.01 & 6.03 & 6.21 & 6.2 \\
\hline 20 & 6.39 & 6.47 & 5.12 & 5.32 & 6.74 & 6.75 & 6.82 & 6.89 & 6.73 & 6.78 & 7.54 & 7.61 \\
\hline
\end{tabular}




\begin{tabular}{|c|c|c|c|c|c|c|c|c|c|c|c|c|}
\hline 25 & 6.52 & 6.82 & 6.22 & 6.41 & 6.9 & 6.92 & 6.5 & 6.96 & 7.2 & 7.31 & 7.5 & 7.41 \\
\hline 30 & 7.27 & 7.30 & 6.92 & 6.98 & 7.86 & 7.84 & 7.63 & 7.85 & 7.21 & 7.23 & 7.66 & 7.67 \\
\hline
\end{tabular}

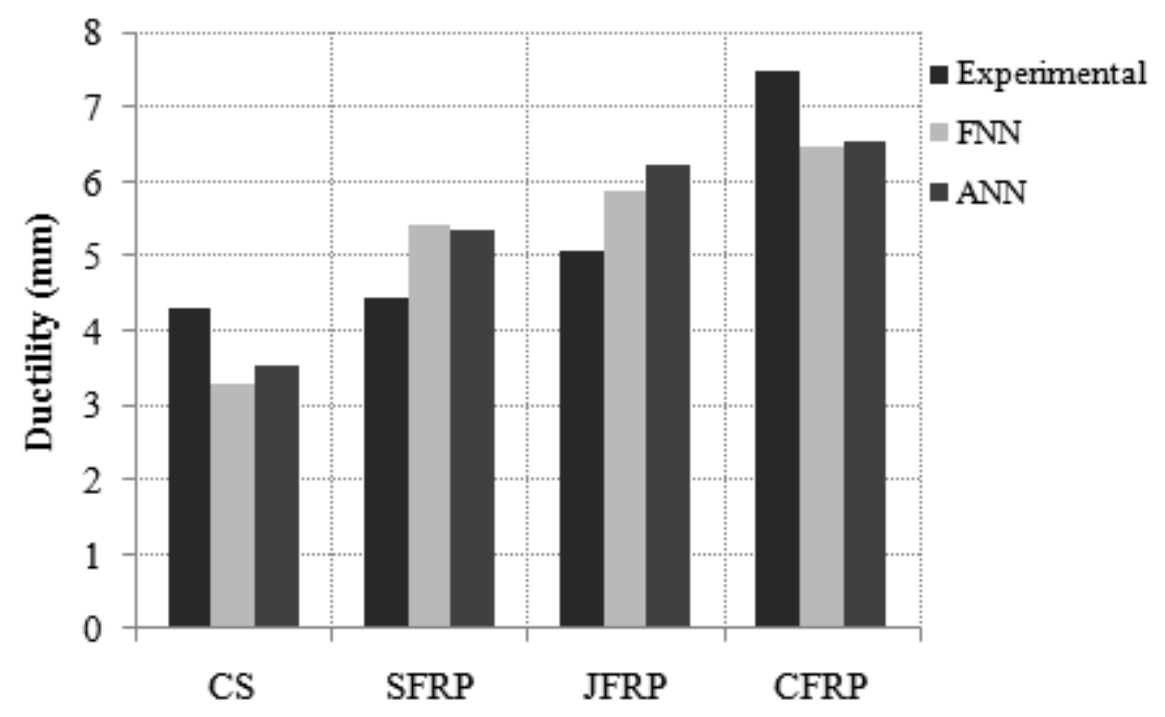

Figure 8: Ductility

Beam-Column Model Characterizations for SFRP, CFRP, CS, R_GFRP, R_BFRP, and JFRP under load variations are explained in tabulation 6. Ductility is the ability of a property to withstand a great deal of adverse conditions without losing its strength. Measured by Ductility Factor. This is the proportion of the failure deflection to the output point deflection. A comparison of ductility between six various models is shown in diagram 8 . The diagram illustrates the value of ductility of the propounded Fuzzy neural network forecasting samples and contrast its presentation with current test esteems and a current ANN Algorithm. The outcomes show that the fiber-strengthened model has higher quality and durability contrasted with the control model.

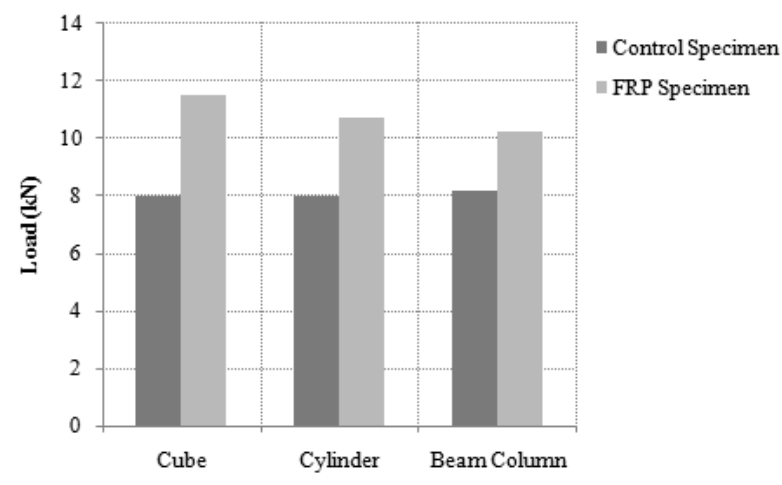

Fig 9: Trail Sample's Load Carrying Capacity

Figure 9 shows the test models load capability such as FRP cube reinforcement, control, beam-column, and the cylinder are examined and illustrated. The FRC load-bearing capacity of the samples was compared with the control sample indicates that the map. 


\section{CONCLUSION}

This study presented the investigation response of HPFRC buildings (CYLINDERS, CUBES, AND BEAM-COLUMN) made with natural fibers such as coir, jute, and sisal. The cyclic loading manner of the developed eighteen models was analyzed, and the effects of fiber reinforced polymer concrete structures are similarly studied utilizing the propounded elements. Boundaries, for example, Tensile strength, Compression strength, Ductility and Deflection were analyzed by predictive examination, fuzzy neural network approach. The optimized esteems are achieved by the propounded fuzzy neural network (FNN), here the definitive yield results are found to be approximately equal to the test data set with the minimum error esteem. The propounded prognosis fuzzy neural network (FNN) sample accomplishes greater exactness in reinforcing investigation contrasted with current models. The upcoming research work related to the reinforcing of high-performance concrete structures; Hybrid blends of natural Fiber training protocols are also associated with forecast samples.

\section{REFERENCE}

[1]. Bruggi, M., \& Taliercio, A. (2013). Topology optimization of the fiber-reinforcement retrofitting existing structures. International Journal of Solids and Structures, 50(1), 121-136.

[2]. Ruano, G., Isla, F., Pedraza, R. I., Sfer, D., \&Luccioni, B. (2014). Shear retrofitting of reinforced concrete beams with steel fiber reinforced concrete. Construction and Building Materials, 54, 646-658.

[3]. Ouyang, L.-J., Gao, W.-Y., Zhen, B., \& Lu, Z.-D. (2017). Seismic retrofit of square reinforced concrete columns using basalt and carbon fiber-reinforced polymer sheets: A comparative study. Composite Structures, 162, 294-307.

[4]. Nair, A., Cai, C. S., \& Kong, X. (2019). Acoustic emission pattern recognition in CFRP retrofitted $R C$ beams for failure mode identification. Composites Part B: Engineering, 161, 691-701.

[5]. Binici, B., \&Mosalam, K. M. (2007). Analysis of reinforced concrete columns retrofitted with fiber reinforced polymer lamina. Composites Part B: Engineering, 38(2), 265-276.

[6]. Carpinteri, A., Lacidogna, G. and Manuello, A., 2007. An experimental study on retrofitted fiber-reinforced concrete beams using acoustic emission. In Proceedings of the 6th international FraMCoS conference (Vol. 2, pp. 1061-1068).

[7]. Dasgupta, A. and Dasgupta, A., 2018. Retrofitting of Concrete Structure with Fiber Reinforced Polymer. International Journal, 4, pp.42-49.

[8]. Awolusi, T. F., Oke, O. L., Akinkurolere, O. O., Sojobi, A. O., \&Aluko, O. G. (2019). Performance comparison of neural network training algorithms in the modeling properties of steel fiber reinforced concrete. Heliyon, 5(1), e01115.

[9]. Barbato, M., 2009. Efficient finite element modelling of reinforced concrete beams retrofitted with fibre reinforced polymers. Computers \& Structures, 87(3-4), pp.167-176.

[10]. Zhou, H., Attard, T. L., Zhao, B., Yu, J., Lu, W., \& Tong, L. (2013). Experimental study of retrofitted reinforced concrete shear wall and concrete-encased steel girders using a 
new CarbonFlex composite for damage stabilization. Engineering Failure Analysis, 35, 219-233.

[11]. Lazo, E.M. and Rinchon, J.P.M., 2018. Hybrid artificial intelligence-based bond strength model of CFRP-lightweight concrete composite. In MATEC Web of Conferences (Vol. 192, p. 02018). EDP Sciences.

[12]. Sood, M. and Dwivedi, G., 2017. Effect of fiber treatment on flexural properties of natural fiber reinforced composites: A review. Egyptian journal of petroleum.

[13]. Irshidat, M. R., Al-Saleh, M. H., \&Almashagbeh, H. (2016). Effect of carbon nanotubes on strengthening of RC beams retrofitted with carbon fiber/epoxy composites. Materials \& Design, 89, 225-234.

[14]. PereraVelamazán, R. and VaronaMoya, F.D.B., 2008. Design of FRP laminates using evolutionary algorithms.

[15]. Baykasoğlu, A., Öztaş, A. and Özbay, E., 2009. Prediction and multi-objective optimization of high-strength concrete parameters via soft computing approaches. Expert Systems with Applications, 36(3), pp.6145-6155.

[16]. Kumar, G.S. and Rajasekhar, K., 2017. Performance analysis of Levenberg-Marquardt and Steepest Descent algorithms-based ANN to predict compressive strength of SIFCON using manufactured sand. Engineering Science and Technology, an International Journal, 20(4), pp.1396-1405.

[17]. Graf, W., Freitag, S., Kaliske, M., \&Sickert, J.-U. (2010). Recurrent Neural Networks for Uncertain Time-Dependent Structural Behavior. Computer-Aided Civil and Infrastructure Engineering, 25(5), 322-323.

[18]. Tarfan, S., Banazadeh, M., \&Esteghamati, M. Z. (2018). Probabilistic seismic assessment of non-ductile $R C$ buildings retrofitted using pre-tensioned aramid fiber reinforced polymer belts. Composite Structures.

[19]. Sharma, R., \&Bansal, P. P. (2019). Behavior of RC exterior beam column joint retrofitted using UHP-HFRC. Construction and Building Materials, 195, 376-389.

[20]. Rescalvo, F. J., Suarez, E., Valverde-Palacios, I., Santiago-Zaragoza, J. M., \&Gallego, A. (2018). Health monitoring of timber beams retrofitted with carbon fiber composites via the acoustic emission technique. Composite Structures, 206, 392-402.

[21]. Rajput, A. S., Sharma, U. K., \& Engineer, K. (2019). Seismic retrofitting of corroded RC columns using advanced composite materials. Engineering Structures, 181, 35-46.

[22]. Xiong, X., Hua, L., Miao, M., Shen, S. Z., Li, X., Wan, X., \&Guo, W. (2018). Multi-scale constitutive modeling of natural fiber fabric reinforced composites. Composites Part A: Applied Science and Manufacturing.

[23]. Sen, T., \& Reddy, H. N. J. (2011). Finite element simulation of retrofitting of RCC beam using sisal fibre composite (natural fibre). 2011 3rd International Conference on Electronics Computer Technology.

[24]. Mini, M. K., \&Sowmya, M. (2012). Neural network paradigms for fatigue strength prediction of fiber-reinforced composite materials. International Journal of Advanced Structural Engineering, 4(1), 7. 